\title{
Knowledge, attitude, and perception of risk management of steam boilers among workers in palm oil mills
}

\begin{abstract}
Background: People who work with the steam boilers in palm oil mills are vulnerable to accidents, notably to explosions, whenever failures of any kind occur during their operation. Objective: This cross-sectional study was conducted in palm oil mills to determine the knowledge, attitude, and perception (KAP) concerning the risk management of steam boilers among workers in palm oil mills. Methods: A total of 50 workers who were working with steam boilers and/or involved in managing the operation of steam boilers with at least three years of working experience in the palm oil industry were purposively sampled. A self-administrated questionnaire consisting of four main parts - socio-demographic and occupational information, knowledge, attitude, and perception of the risk management of steam boilers was distributed. The knowledge, attitude, and perception were calculated based on a Likert-type scale. Results: This study found that $56 \%$ of boiler workers had a good level of knowledge (mean score = $77.22 \pm 19.6$ ), $72 \%$ had a good attitude toward risk (mean score $=83.17 \pm 5.85$ ), and $64 \%$ had a good perception of risk (mean score $=79.50 \pm 11.22$ ). The prevalence of accidents was $16 \%$, and, for near misses, it was $24 \%$. The cause of the reported accidents was largely attributed to carelessness, specifically at $80 \%$. Apart from that, there was a positive association $(\chi 2=6.56$; $\mathrm{p}=0.010$ ) between attitude and accidents. Conclusion: This study found that the workers had good KAP levels of risk management of steam boilers in palm oil mills. However, there is a need for the employers to revise the training of workers and ensure its effectiveness in heightening the awareness of risks and accidents despite the high level of KAP.
\end{abstract}

Keyword: Hazards; Occupational health; Prevalence; Training 